\title{
Review of History in the Development of Esthetics in Dentistry
}

\author{
Sheetal Chowdary Bolla, Naga Sribala Gantha, Riyaz Basha Sheik
}

\begin{abstract}
The face is the most visible part of the human anatomy and determines our social appearance. Facial appearance is of great concern to every one for it is a significant part of the self image. It is customary that we greet our friends and relatives with our smiling faces. Face has been defined as a chart of destiny, an impression of fullness of life, and mirror of soul. The loss of teeth, because of the effect on facial appearance often causes psychological trauma. Nature has endowed everyone with dignity and satisfaction of being an individual personality. The study has been done to know the history in the development of esthetics in dentistry.

Keywords: Esthetics, Teeth, Dentures, Face.
\end{abstract}

\section{Introduction}

Face has been defined as a chart of destiny, an impression of fullness of life, and mirror of soul. The loss of teeth, because of the effect on facial appearance often causes psychological trauma. Nature has endowed everyone with dignity and satisfaction of being an individual personality. Beauty lies in the eyes of the beholder, in the same way while selecting the teeth or arrangement pattern one should visualize the patient as a whole. The term "esthetics" was coined in 1750 to designate the science of sensuous knowledge, which gave beauty, in contrast to the science of logic, which gave truth. It is derived from the Greek word "Aesthesis"1 According to the Glossary Of Prosthodontic Terms, esthetics can be defined as pertaining to the study of beautiful. Descriptive of a specific creation that results from such a study; objectifies beauty and attractiveness and elicits pleasure.2 Webster's Third New International Dictionary defines esthetics as appreciative of, responsive to or zealous about the beautiful; having a sense of beauty or fine culture.3 Esthetic fundamentals are beauty, naturalness and individuality and it is idealizing or harmonizing of the artificial with the natural. Esthetic is the science with established rules and an art necessitating skill and taste in accordance with esthetic principles.

\section{History In The Development Of Esthetics}

Assyrio -Babylonian cuneiform tablets dating from the dawn of recorded history advise the following: "if a man's teeth become yellow ... thou shalt bray together "salt of akkad", ammi, lolium, pine- turpentine with these, with thy fingers shalt bur his teeth".4

Writing in the ninth century BC, the author of the song of Solomon (4:2) offers a poetic description of dental esthetics: "Thy teeth are like a flock of well selected sheep, which are come up from the washing, all of which bear twins, and there is not one among them is deprived of her young". Whether Egyptians concerned themselves with prosthetic dentistry is at least questionable. Hidden in a shaft attached to a burial chamber at Gizeh from 2500BC were two teeth connected by a gold wire.5 In the region of the north western neighbor of Israel, a Phoenician female's maxilla was found with anterior teeth held together by a gold wire. This ancient Phoenician bridge has pontics that are extracted central and lateral incisors that are attached to the remaining canines with wires (fourth century BC).4

In the ancient Japan, skillful dentures were carved from hardwood with nail heads as grinding surfaces, and flint or mouth of pearls platelets was set in the anterior teeth. The central and South American Mayas (approximately $1000 \mathrm{AD}$ ) beautified themselves by filling the incisal edges of their anterior teeth into various shapes and designs. Romero (1951) reported the existence of 51 different artifacts incrustations, which could be separated into three groups;

1. Filing of the tooth contour

2. Filing and inlays on the anterior surface

3. Combinations.

The Mayas placed plugs of iron, pyrites, Obsidian and jade into the labial surfaces of maxillary anterior teeth as inlays, a practice followed in both the sexes. In the Achual tribe (INCA) of upper Amazon region in 1969, the custom among men to blacken their teeth with leaves from the piu and Nashumbi bushes was reported. The leaf was folded, held between fingers, rubbed along the teeth and chewed vigorously. The occlusal surface remained light, while the crown developed a black coating. Between 1540-1550, roun and rectangular inlays were found that are worthy of attention in the Ecuador village. The village chiefs used these as a kind of privilege or distinction. Rectangular inlays adorn the labial surfaces of anterior teeth where a groove is recessed in the 
cutting edge and the gingival margin. Artifacts of tooth truncation (a custom imported with the first Negro slaves from Africa) were noted in1969 among a race of Ticuna in Amazon River region. They still file their teeth, even today. In the eighth or ninth year of life this procedure was considered a ritual. 6

\section{Modern Dental Esthetics}

The interest in dental esthetics was virtually absent during the middle ages. It was not until the 18th century that dentistry was recognized as a separate discipline and its various branches were established. The leader of the movement to modernize and promote dentistry was Pierre Fauchard (1678-1761). He, together with several colleagues, advocated such esthetic practices as proper oral hygiene and the use of gold shell crowns with enamel "veneers". 4 Fauchard's most fruitful activities were in the area of prosthetics as he, in contrast to his predecessors, described every detail of technical methods. The materials, which were coming into fashion for prosthesis, were human teeth, ivory, hippopotamus bone, and walrus tusks. For replacement of individual teeth with human teeth, the root was filed off, dental pulp filled with lead and the crown was drilled through, threaded with twine or silk, and made fast to the neighboring teeth. For several teeth, they were riveted to a gold wire or splint. Complete lower dentures, shaped on a lathe in one piece from bone, rest by their own weight on the arch of the jaw. Upper dentures on the other hand, held by flat springs, which support themselves on the mandible. Also, complete upper dental arches can be fastened in this manner to complete lower arches. These steel springs (only very fragile springs made of fishbone were known previously) were also seen in a 16th century grave, where crude dentures carved from ox bone are connected by two strips of metal, which allowed certain degree of mobility, and perhaps, even possessed a light spring effect. Fauchard also used the fishbone springs criticized before, but fortified them with wire springs.

Bourdet, probably the most significant author after Fauchard, designed prosthesis for an extensively resorbed jaw. He would have a base of gold with two holes on each side through which the silk customarily used for fastening to neighboring teeth can be threaded. In this base, there are small chambers (chatons) like the sockets, into which shortened roots of the corpse's teeth are inserted.7 In the Colonial United States, primitive dental conditions prevailed for almost century (1670-1770) until the arrival of "operators for the teeth"- dental professionals who had been trained in Europe. They brought with them, not only medications for toothache, but also prescriptions for tooth powder "to make teeth white" and attend to your teeth and preserve your health and beauty". They claimed their toothpowder "prepared" and "fixed" real enameled teeth, the best contrivance yet to substitute the loss of natural ones. Transplantation of teeth between patients was practiced, with donors being paid for their trouble-"any person that will dispense of their front teeth, five guineas for each." Cosmetic dentistry did not meet with universal acceptance, however. The following is an official edict published by His Britannic Majesty at Perth Amboy, New Jersey:

All women of whatever age ,rank, profession or degree, whether virgins, maids or widow, who after this act shall impose upon, seduce and betray unto matrimony any his majesty's subjects by virtue of cosmetics, scents, washes, paints, artificial teeth, false hair or high heeled shoes, shall incur the penaly of the law in force against witchcraft and like misdemeanors." Competent dental practitioners could be found in the leading cities of the United States by the early years of the 19th century. The introduction of mineral teeth in 1817 was soon followed by the manufacture of porcelain teeth. Dentures were fabricated with a gingival component made of carved ivory or animal bone that was designed for adaptation to ivory or bone bases.

These denture bases were common until the 1850 s, when various alternative materials were introduced to afford more esthetic results. The technique of mounting artificial teeth on gold or platinum fused with continuous pink gingival body made of porcelain was patented in the 19th century. "Auroplasty" colored Guttapercha; "Parkensine" Celluloid like material; "Cheloplasty" an alloy of Tin, Silver and Bismuth; "Rose Pearl" Colloidion; Pink Hecolite; and even Tortoise shells were used for esthetic effect in dentistry.

\section{Complete Dentures For Esthetics}

The delivery and adjustment of complete dentures have an indirect but important effect on esthetics. This phase is often neglected and the patient is expected to adapt automatically to the new dentures. A clinical remount is essential along with the use of pressure indicating paste and disclosing wax. Patients who are relaxed and comfortable with their new complete dentures are likely to have a more pleasing appearance. Patients should be cautioned not to judge the total esthetic effect until they are relaxed and comfortable. The perioral musculature may have a strained appearance until the patient feels confident. 8

Written instructions should be provided for all patients receiving removable prosthesis and salient aspects should be reinforced verbally during the delivery appointment. The importance of periodic recall appointments should be stressed not only for continued tissue health and proper function of complete denture, but also for preservation of esthetic perception. 
Prosthodontics - Satisfying the Esthetic Need

Prosthodontists cannot ignore the increasing demand for elective dental procedures. They must acknowledge the shifting dental perceptions of patients and appeal to the esthetic need. The advanced training of Prosthodontists makes them uniquely qualified to successfully deliver esthetic services and position themselves as the primary providers of esthetic dentistry.

A prosthodontic reconstruction can completely alter the facial appearance of the treated patient. The techniques that have fueled the esthetic revolution clearly fall within the domain of prosthodontics.

Patients can then assess the risks and benefits of elective esthetic procedures. Owall reminds Prosthodontists that the quest for dental esthetics may inflict significant biologic costs and compromise their main goal, to restore or rehabilitate inadequate function. Some dentists may have compromised the basic dental needs of comfort and function in the pursuit of improved esthetics, and dentistry performed solely for esthetic enhancement could result in over treatment. On the other hand, current techniques for elective esthetic procedures might be less traumatic than those used previously. The second core competency of Prosthodontists is their treatment planning skills. Beginning in their residency programs, Prosthodontists learn how to coordinate efforts with general dentists and other specialists. Achieving optimal esthetic outcomes often requires the involvement of several dental and even medical professionals. Because this multidisciplinary approach will be more prevalent in the future, the prosthodontist's treatment planning skills will be essential in leading the treatment team.

\section{Summarizing Esthetic Concepts Through The Years}

\section{Esthetics versus function}

Some studies regarding predictors of complete denture success failed to show esthetics as more important than function or comfort. These studies often review patients from Veterans Affairs hospital settings, where one would expect function and comfort to be preferred to esthetics. The psychological importance of a pleasing dental appearance is clear and is often discussed in regard to denture success. Despite the fact that solutions to functional and comfort-related problems are available, successfully restoring the appearance of an edentulous patient remains problematic.

\section{Early concepts-temperamental and typal}

The earliest dental restorations were created for appearance alone with no thought to function. This continued to be the case with early porcelain dentures in 18th century France. As dentistry became a profession, the early literature reflected the importance of esthetics. White introduced what is probably the first esthetic concept when he described his theory of correspondence and harmony. White described this theory as a correspondence between tooth form and color in harmony with age and gender.

This was later accepted as the temperamental theory of denture construction. It was based on the idea that a subject's temperament or bodily characteristics matched the size, proportion, arrangement, and color of the teeth. Some interesting ideas highlighted by this early esthetic concept included (1) the relationship between age, gender, and appearance, (2) the proper tooth-to-face-size proportion, and (3) color harmony between face and teeth. The inability to agree on a specific prosthetic tooth for a certain temperament or to decide which temperaments existed limited this system's practical usefulness. The early authors on denture esthetics did agree, however, on a significant point: denture esthetics required realizing a basic principle in human appearanceindividuality. It is of note that much attention was paid to the esthetic aspects of denture construction prior to the advent of sophisticated functional concepts and prior even to the regular use of articulators.

Past and current research has shown that no significant correlation exists between facial form and tooth form. Using the typal form concept clinically is complicated by facial form appearance alterations due to age, hairstyle, eyewear, and body mass changes. In the same discussion used to disprove the temperamental theory, Wllliams then introduced the typal form theory and stated that: nature does not always produce a definitive type of tooth for a given form of skull. Williams later admitted the artistic nature of esthetics by stating that some tooth forms appear more harmonious with certain types of faces. This was the same conclusion made by the proponents of the temperamental concept. As details of denture construction continued to be investigated, emphasis switched from tooth selection to tooth arrangement.

\section{Dentogenics}

Frush and Fischer used the early ideas of Sears to help establish the dentogenic concept of denture construction. These authors wrote that gender, personality, and age could be used as guidelines for tooth selection, arrangement, and characterization to "enhance the natural appearance of the individual. Other authors have also discussed aspects of natural appearance in complete denture fabrication. The success of the dentogenic concept coincided with great advances in denture materials. As reliable acrylic resin became available, the ability to 
achieve esthetic results improved considerably. Denture teeth, base material, and gingival tints could now precisely match the form and color of the tissue being replaced.

Most would agree that prediction of a personality is more subjective. However, one study showed that different denture tooth arrangements do project different personality traits. The author concluded that characteristics of tooth morphology and arrangement could elicit biases from the viewer. Several authors have attempted to predict patient gender and age by showing denture tooth arrangements or oral photographs. An ability to predict gender or age was not shown. These studies failed to assess the teeth from an extraoral perspective, as they would be seen in public. Frush and Fischer noted that a restoration can only be evaluated in the mouth. Proper analysis of the dentogenic effect would include the patient face and would, therefore, bias the results of the previously mentioned studies.

\section{Modern concepts-patient involvement and preference}

The next advancement in denture esthetics was an article on the principles of visual perception detailing the use of standard artistic principles. The assumption was that the denture is a work of art and should, therefore, be held to the same standards of viewing as paintings or sculptures. The primary guideline is to attempt dynamic unity, also called unity with variety. The entire dental composition should be complimentary to the face and to itself. At the same time, it should not be mechanically straight or without uniqueness. Proportion, line, dominance, balance, and color are some of the specifically applied principles. The article is important because of its scientific approach to the artistic nature of denture construction. This fact makes the article, in the author's opinion, the most comprehensive statement on denture esthetics to date.

A key component of the article is the assertion that making the patient appear natural might not necessarily be the goal. In fact, through use of the artistic principles, Lombardi seems to suggest that an ideal smile can be created. Increasing patient involvement to achieve this goal was a much different approach than earlier models, which relied on the dentist for esthetic decision-making. If the patient is involved in esthetic decisions, patient preference for certain attributes becomes important. If the dentist understands what the patient prefers, the chances for miscommunication are likely to be decreased.

These studies have either evaluated the effect of patient involvement on esthetic preference, personality determinants of esthetic preference, or esthetics versus function. When patient preference is considered, there is a lack of scientific guidelines for tooth arrangement in an edentulous population.

Dentate patient research

Although the literature may be lacking for edentulous patient preferences, several studies have analyzed dentate patient preference for tooth appearance. One study was conducted in the form of a questionnaire alone, and another included photographs without direct questions about the teeth. The earliest patient-preference study used close-up photographs of maxillary incisor teeth to determine preference for tooth size, shape, proportion, and arrangement symmetry .In another study focused on incisor angulations alone. These two studies are limited because they showed respondents only the tooth arrangements. When showing only the teeth, it is not surprising that perfectly straight arrangements are preferred. To obtain a true assessment of preference, the teeth should be shown with the face since this is how they will be evaluated in public.

Using computer-aided photographic image manipulation, several authors have been able to control variables in measurements and facial appearance. The first of these studies examined the effect of tooth size, form, color, smile line, and midline diastema while still showing the entire patient face. Another study using a photographbased questionnaire examined the effects of tooth positioning and arrangement.

Applying dentate research to edentulous patients

Three esthetic concepts

The most effective studies previously reviewed used oral images with no signs of aging. The subjects would, therefore, be considered youthful in appearance. In addition, the respondents to the esthetic preference surveys were not differentiated into age groups. If an elderly patient has the same esthetic preferences as those of a younger patient, he or she may not want a dentogenic restoration. Unfortunately, the existing evidence regarding the preferences of complete denture patients, who tend to be older, is limited to the articles presented in this review.

This defines the difference between the two major esthetic concepts of complete denture construction: dentogenic restorations seek to match anatomic determinants of gender, age, and personality, whereas a patientcentered approach allows alterations from what may be normal to provide patients with what they regard as beautiful. The author of this article describes these two concepts as natural and supernormal.

The third esthetic concept developed as a result of common errors in fabrication and appearance for complete denture wearers. It has been described as a "denture look". Despite agreement in the literature that a denture look is not acceptable, elderly patients may be accustomed to such an appearance. Likewise, if a denture 
look is associated with elderly appearance, patients may expect and even prefer to have such an appearance. This idea has not been investigated in the literature.

\section{Universal esthetic goals}

This review demonstrates the limited amount of information available for restoration of dentate appearance in edentulous individuals. The historical literature presented in this review demonstrates that the majority of esthetic guidelines used in complete denture fabrication are based on the suggestions of clinicians. Unfortunately, these ideas may be misleading or incorrect. Two examples discussed earlier are the inaccuracies of the incisive papilla and the lack of correlation in the typal form theory of esthetics. The lack of existing guidelines is also evident in the latest edition of the principles, concepts, and practices by the Academy of Prosthodontics.

Fortunately, the above demonstrates several esthetic goals when considering the two major esthetic concepts of natural or supernormal appearance. A 100-degree nasolabial angle and a 140-degree mentolabial angle should be the goal for the extra oral appearance in a white population. The incisal edges of the maxillary teeth should follow the lower lip line, and a reverse curve should be avoided. The dental midline should be both coincident with the facial midline and vertically straight. A gingival-to-Lip distance of $4 \mathrm{~mm}$ or more may be considered unaesthetic. These factors should be considered baseline esthetic guidelines in complete denture construction. As this review has shown, specific decisions about tooth display, proportion, size, shape, arrangement, color, and, to some extent, position are based on which esthetic concept the patient and dentist have chosen.

\section{Conclusion:}

Dental art does not occur automatically. The dentist must purposely and carefully incorporate it into the treatment plan. This artistry tries to soften the marks imposed upon the face of time and enables people to face their world with renewed enthusiasm and confidence.Research in the field of esthetic dentistry still continues. Today, dental esthetics is founded on a more ethically sound basis; the general improvement of dental health. But the same desires of those ancient men and women to submit to dental decoration as an outward portrayal of the inner self motivate today's adults to seek esthetic treatment. Although esthetic dentistry can help achieve self-assurance, it must always be predicated on sound dental health.

\section{References}

[1]. Young HA, Denture Esthetics, J Prosthet Dent 1956; 6 (6), 748 - 755

[2]. The Glossary of Prosthodontic Terms. J Prosthet Dent 2005; 94(1): 10 - 92.

[3]. Theory of Beauty : Webster's International Dictionary, ed. 3

[4]. Asbell MB. Introduction to Esthetics. In Esthetic Dentistry - A clinical approach to techniques and materials by Ashheim KW, Dale BG, Mosby 2nd Ed. 2001. p 23 - 26.

[5]. Walter Hoffmann - Axthelm. The Ancient Orient. In 'History of Dentistry': Quintessence, 1981, p 19 - 34

[6]. Walter Hoffman - Axthelm. Pre - Columbian America. In 'History of Dentistry' Quintessence, 1981, p 47 - 59.

[7]. Walter Hoffman - Axthelm. The 18th Century Dentistry becomes Independent. In 'History of Dentistry'. Quintessence 1981, p 194 $-246$.

[8]. Zarb GA. Bolendar CL, Hickey JC and Carlsson GE. Biologic considerations in vertical Jaw relations. In 'Boueher's Prosthodentic Treatment for Edentulous Patients : BI Publications Pvt. Ltd. 10th ed. p 272 - 281 